\title{
Discursive Representation of the EU in Brexit-related British Media
}

\author{
Reem Alkhammash \\ reem.alkhammash@gmail.com \\ English Language Department, University College, Tarabah, \\ Taif University, Saudi Arabia
}

\begin{abstract}
Coverage of the Brexit referendum dominated UK media in the summer of 2016. Previous research has focused on the Leave-leaning press and the representations of politicians within that debate. Analysing the British media representation of the EU is paramount in understanding dominant, conflicting discourses regarding the decision of British voters in the period preceding the referendum. This study compares language use in conflicting discourses of Brexit in British media by adopting a corpus-based discourse analysis using the Brexit corpus in Sketch Engine. Drawing on two corpus methods, namely concordance analysis and collocation analysis of the lexis under study (i.e., the term 'EU'), results of the analysis show that in the Leave campaign, the EU is represented in a negative sense in that continuing to be a member of the EU is viewed as bringing certain economic danger to the future of the UK and as increasing the prospect of terrorist attacks. However, the EU is represented in the Remain campaign both positively and negatively. It is represented positively in that the British public is reminded that the UK shares similar values to those held by the EU and negatively in that the media are critical of the EU in its current form. The Remain campaign also dismantles narratives made by the Leave campaign detailing the benefits of exit to British sovereignty and economy. This article concludes with a discussion of the dominant discourses about the EU found in the British media.
\end{abstract}

Keywords: corpus-based discourse analysis; Brexit; discursive representation; EU; conflicting discourses

\section{INTRODUCTION}

The complexity of Brexit is unprecedented in British history. The 2016 decision to vote either to leave or to remain in the EU reflected a more complex situation than a mere division between two parties in British politics (Harris, 2018, and Bennett, 2019). The divided public opinion was a manifestation of differing value systems and strong attitudes held by different classes and political affiliations in British society. Such disagreement was formed over years and was specific to the British political sphere. In the British public discourse, views over Brexit were affected by British voters from certain demographics and classes. Remain voters, who were more likely to support the Labour Party, came from urban areas and were most likely to be young and educated, while the Leave voters supported the Tories and came mostly from working-class backgrounds. Of note as well is the shift of the working class from the Labour party it had historically been linked to into the Conservative Party and the UK Independence Party (UKIP) (Zappettini \& Krzyżanowski, 2019).

With regards to Brexit, contemporary British media outlets have been actively engaged in populist views. Gaston and Harrison-Evans (2018), for instance, argue that populist ideology is an emergent, powerful narrative in the UK and that the rise of populist rhetoric is attributable to populist leaders who have been divisive regarding the UK being a member of the European Union. In discourses pertaining to Brexit, many topics are prominent in both the Leave and the 
Remain campaigns, including immigration, British economy, Europe, the EU, the environment, multiculturalism and globalisation (Harris, 2018). Yet, some topics are more likely to be associated with the Leave campaign, such as immigration, and others with the Remain campaign, such as multiculturalism.

This study focuses on how the EU is represented by both the Leave and the Remain campaigns in media discourses on Brexit taking place shortly before the referendum. The Brexit debate has been described as containing new imaginings and representations of the British people (Clarke \& Newman, 2017). The chosen topic is selected because it is common to both campaigns. In addition, the EU has been subjected to re-narration in the British public debate and thus brings political as well as cultural significance to the discourse of Brexit in the media (Maccaferri, 2019). The study implements a corpus-based discourse analysis framework with particular focus on concordance analysis and collocation analysis to reveal discursive patterns and to draw a general comparison between the two campaigns. The study begins with a review of the relevant literature, followed by a discussion of the Brexit corpus and the method of analysis used. Finally, the results of this study will be presented and discussed.

\section{REVIEW OF RELATED STUDIES}

Many researchers have investigated discourses pertaining to Brexit in media and political spheres (see Koller, Kopf \& Miglbauer, 2019). For example, a theme session has focused on the discourses of Brexit in the media and took place in Critical Approaches to Discourse Analysis Across Disciplines conference (see Hansson, 2018, Zappettini, 2019, and Wenzl, 2018). The interest in analysing Brexit discourse has been driven by a need to detangle the many motivations for the decision to leave the EU and the socio-political consequences of Brexit (see Weißbecker, 2017 \& Aluthman, 2018). With the emergence of populist ideology in public spheres around the world, researching discourses of Brexit is timely as a case study; it may provide insights helpful in corpus-based discourse analysis and may lead to a better understanding of the relationship between discourse and the ideological underpinnings governing populist rhetoric.

Thommessen (2016) conducts a study on the representations of Leave voters in 12 articles in British newspapers. The study analyses legitimation strategies such as voice, listening, and othering as a discursive strategy in the discourse of the Leave voters, using critical discourse analysis as a theoretical and methodological framework. The analysis of the left-leaning British newspapers shows that they construe arguments used by Leave voters as illegitimate, whereas right-leaning British newspapers tend to display an understanding of the Leave stance by drawing on history to explain the position of the Leave voters. Similarly, Weißbecker (2017) investigates a British conservative politician who urges voters to vote Leave. She analysed Michael Gove's speech entitled 'The Facts of Life say Leave' using Ruth Wodak's Discourse-Historical Approach. She found out that the arguments used by Michael Grove rely on misrepresenting the EU and delegitimizing the Remain voters through ridiculing their position. She further explains that Michael Grove has depicted the UK to be in danger and ridiculed the stance of the Remain camp using the de-legitimisation as a discursive strategy.

Krzyżanowski (2019) investigates discourses of crisis in Europe by analysing the intersection of Brexit and crisis in the newspapers of four European countries. Krzyżanowski defines crisis in discourse as an 'array of international crisis imaginaries often rooted in scenarios of future course of actions and events' (Krzyżanowski, 2019, p. 466). The study employs a discourse-conceptual analysis which combines frameworks from the discoursehistorical approach in critical discourse analysis and conceptual history. The analysis adopted aims to explore the key arguments, classic topoi, social actors, presuppositions, prelegitimation of practice and fallacies used in framing Brexit as a crisis in European media. The 
results show that the European public sphere views the event of the UK leaving the EU as a negative crisis with destructive consequences for the UK, the EU and the world. This concept of an imaginary crisis is tied to a scenario in the future and is dominant in European media discourses.

Leung (2018) analyses the political discourse of Brexit with particular focus on three speeches of Prime Minister Theresa May, using insights from systematic functional linguistics. The analysis of the PM's three speeches concludes that each speech is aimed for different audiences. For example, the Lancaster House speech is aimed to address concerns for the British public and the experiential themes are found to be more common in referencing the British society to augment the voices of the British public. Also, both the oral statement and the notification letter of Article 50 are aimed to address the British Parliament and has referenced the EU using an inclusive pronouns such as we because the analysis suggested that the PM's wanted to form so kind of solidarity before the negotiation with the EU.

Ballmann (2017) compares media representation of Brexit in three media outlets: Deutsche Welle, France 24 and Aljazeerah English. The study adopts a critical discourse analysis approach and a framing analysis to analyse the data. The results show Brexit as a transnational topic and reveal that the three media outlets equally frame Brexit as a conflict (political, economic and social/cultural) resulting in an economic consequence for the UK's association with the European single market. Of interest is that Brexit triggers national and international interests in all the three media outlets with similar distribution. While previous research has begun to explore the media representation of Brexit, the analyses have focused primarily on legitimization strategies, systemic functional analysis and framing analysis. This study fills a research gap by adopting a comparative analysis of the Leave and the Remain campaigns. The two delineated and divided points of views and ideological division of parties deserves a close analysis that draws on their points of contentions and similarities. Such analysis will reveal the discursive construction of the EU of these conflicting views in the British media.

\section{RESEARCH QUESTIONS}

This paper addresses two research questions:

RQ (1): What does a concordance analysis of the term 'EU' in the Brexit corpus reveal with reference to the Leave and the Remain campaigns?

RQ (2): What does the term 'EU' collocate with? What are the similarities and differences between the Leave and the Remain campaigns' discursive patterns?

\section{METHOD}

\section{DATA}

Data were collected shortly before the date announced for the Brexit referendum (June 23, 2016) and consisted of Brexit-related thematic news, comments and weblogs. Through the European grant, the corpus was collected by the University of Trento, Websays.com and Aix Marseille University and were accessible through Sketch Engine. The Brexit corpus size is $4,789,571$ and the data captured the media coverage of the Brexit debate up until the day before the election from $19^{\text {th }}$ of June to the $21^{\text {st }}$ of June 2016 . The Brexit corpus was coded according to sentiment expressed, topic and opinion. The Brexit corpus was selected because it provides an excellent representation of British-related media before the UK referendum. In addition, since the Brexit corpus was classified into 13 different sub-corpora, the wide variety of classified corpora allows more refined comparative linguistic analysis of conflicting views, 
namely those who support Brexit and those who do not. Two of the sub-corpora were classified into views that either support leaving the EU or remaining in the EU and these two sub-corpora were selected for this study to carry out the comparative analysis. The Leave against EU subcorpus has 239,419 tokens and represents $4.14 \%$ of the Brexit Corpus while the Remain for EU sub-corpus has 191,185 tokens and represents 3.3\% of the Brexit Corpus. To answer the research questions, a corpus-based discourse analysis was employed which triangulates quantitative and qualitative tools, providing generalisable results (Marchi \& Taylor, 2009).

\section{CONCORDANCE ANALYSIS}

Concordance analysis is one of the most widely used tools in corpus linguistics. In order to conduct the concordance analysis, human knowledge is required to identify relevant meanings, repetition and functions in the discourse under investigation (O'Donnell, 2008). Concordance software is also employed, including Wordsmith or Antconc. More recently, web-based concordance analysis is performed, whereby a search for key words or phrases generates many concordance lines of the word/phrase comprising nodes of surrounding words. Many methods are found in the literature incorporating concordance analysis of textual data. For example, Sinclair (1999) suggests investigating concordance lines in such a way that a random selection of 25 lines in the corpus is selected for multiple cycles of analysis (iteration). The purpose of iteration is to discover new information with each stage and to have a representative portion of the data in the analysis. Another method employs a one-time random sampling (Xiao, 2009). The present study analyses the concordance lines of 10 random instances of the term 'EU' in both the Leave and the Remain campaigns. The concordance analysis afforded insights into the conflicting discourses and the context under investigation.

\section{COLLOCATION ANALYSIS}

Firth (1957, p.11) famously stated, 'you shall judge a word by the company it keeps'. Sinclair (1991, p.170) provides the most cited definition of collocation: 'the occurrence of two or more words within a short space of each other in a text'. According to Baker (2006), a collocational analysis is worthwhile for investigating discursive representations for two reasons: assisting the researcher in the initial stage of research to identify lexical patterns and unravelling the most salient lexical patterns concerning the topic of investigation. In collocational analysis, the researcher must define a 'window', or number of words to the left and right of the collocate under investigation. The analysis of collocation permits the researcher to identify the grammatical structure of the collocates and to determine the minimum occurrences of the collocates and measure its significance (see Partington, 1998).

Collocation analysis of 'EU' includes a semantic analysis of the collocates associated with 'EU' in the Leave and Remain campaigns (see Sinclair, 1991). The collocates under investigation have the window of five words to the right and left of 'EU' and have the minimum frequency of five. This close analysis of collocates may contribute to our understanding of the construction of minority groups or political entities by revealing the stance of media discourses (see Baker, et al., 2007). This study used Sketch Engine for the collocation analysis (Kilgarriff et al., 2004). A general, 'broad-brush' approach was taken to the analysis of collocations (Baker, Gabrielatos \& McEnery, 2012), in which the analysis presented common collocates with 'EU' for the purpose of revealing discursive patterns associated with the Leave and the Remain campaigns in British media. This study used logDice reported by Sketch Engine and is a statistical score that measures the association of collocations with its grammatical class (Rychly, 2008). 


\section{RESULTS}

\section{REPRESENTATION OF THE EU IN THE LEAVE CAMPAIGN}

The concordance analysis of two opposing campaigns, namely the Leave and Leave against EU sub-corpus and the Remain and Remain for EU sub-corpus, generate significant findings regarding the term 'EU'. The analysis begins with an advanced search via the concordance function in Sketch Engine of the term 'EU', a common acronym for 'European Union' in both the Leave and the Remain campaigns. The term 'EU' has the frequency of 2165 (1720 times per million) in the Leave and Leave against EU corpus. Figure 1 below shows the concordance analysis.

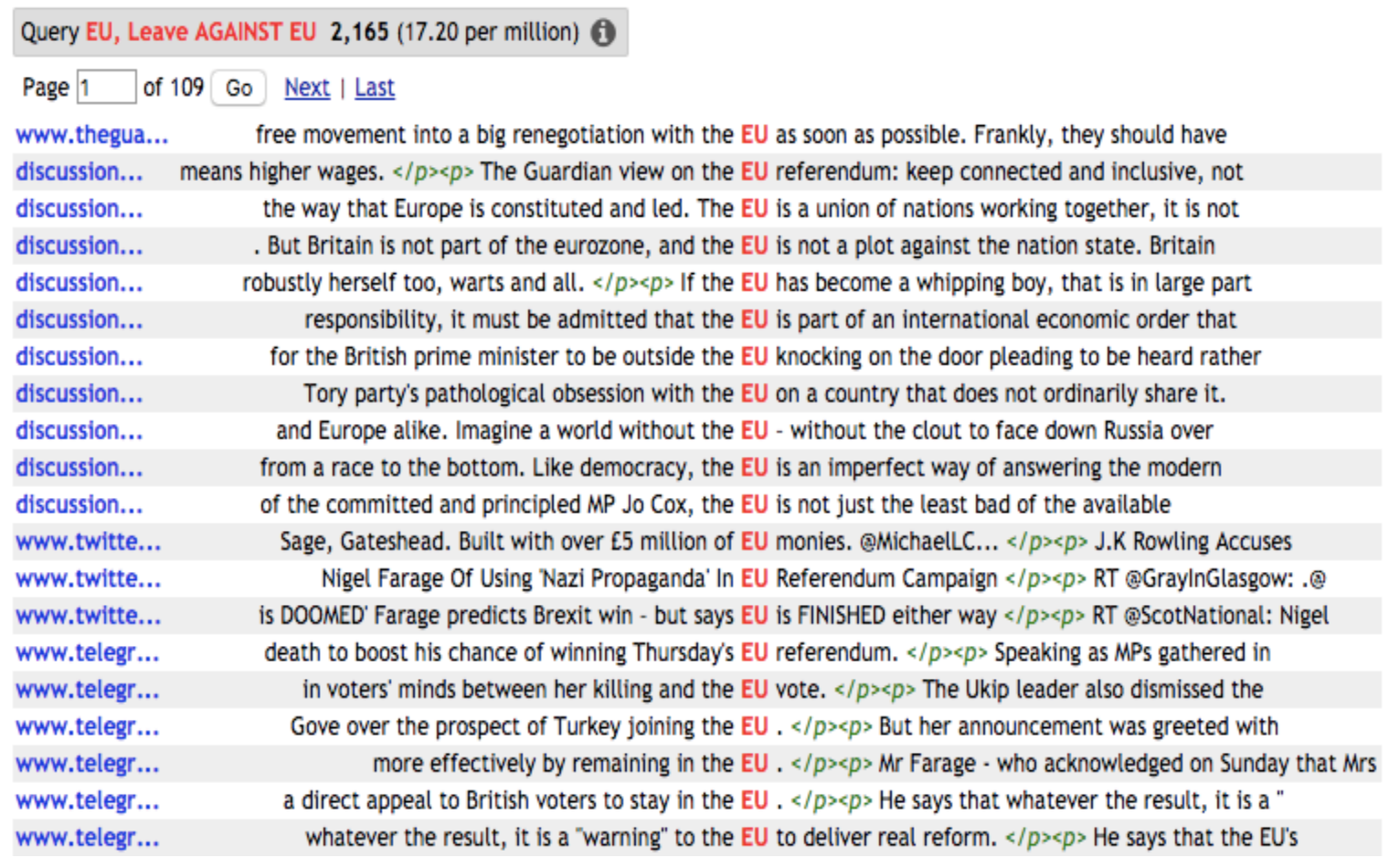

FIGURE 1. Concordance analysis of 'EU' in the Leave against EU corpus

In the concordance analysis of 'EU' in the Leave campaign, 10 instances of 'EU' were selected randomly for a closer analysis. Examining randomly selected sample of 10 instances of the lexis under investigation is aimed to show detailed discursive patterns (see Baker, 2010). I sorted the instances of the EU by classifying the different instances in the 10 random selected concordance lines by meaning, identified key words and figurative expressions. The numbers in the analysis below indicate the concordance lines of the 'EU' in Figure 1. The EU is challenged as an economic power which benefits local British workers in the Leave campaign. Ireland is named as a contender more likely to benefit British workers than its EU counterparts (line 1). In the same vein, the EU is stated to have a detrimental effect on the British economy through the use of the word 'shackles' (line 2). The EU is represented to be failing economically; therefore, exiting a failing EU is considered 'arriving into' a better future (line 5). Appealing to the sound judgment of British readers, the Leave campaign urges the British public to think of the future of their children as free from a 'corrupt EU' (line 3). The EU is represented in a negative sense in which only the EU would bring danger to the UK in the form of conflict, terrorism and massive Islamic immigration (line 4). The Leave campaign disregards the shared history with the EU and considers the European value system as out of sync with 
British values (line 6). In the Leave campaign, the argument made by Labour Party leader Jeremey Corbyn is confronted with a question about the particulars of his proposal to change the terms of the UK's agreement with the EU (line 7).

Other common topics associated with 'EU' in the Leave campaign include the notion of a lack of trust in powerful economic organisations in the UK such as banks. Banks are accused both of looking out for their corporate interests rather than the interests of the British people or the British economy and of an inability to solve youth unemployment (line 8). The Leave campaign juxtaposes the stance of then-Prime Minister David Cameron, a supporter of the Remain campaign, regarding the inclusion of Turkey in the EU and his lack of ability to regulate EU immigrants (line 9). The Leave campaign attempts to dispel rumours of the negative economic effects of withdrawing from the EU, namely price inflation, by claiming that business relations will remain the same with the EU after Brexit (line 10).

Figure 2 shows the collocation analysis of the term 'EU' in the Leave campaign. The figure illustrates the raw frequency of each collocate, the grammatical class of each collocate and the $\log$ Dice results. The term 'EU' has a raw frequency of 43,704 (5,629,52 times per one million) in the Brexit corpus in the sub-corpus of Leave against EU.

\begin{tabular}{|c|c|c|c|c|c|c|c|c|c|c|c|}
\hline \multicolumn{2}{|l|}{ modifiers of "EU" } & 0.64 & \multicolumn{3}{|c|}{ nouns and verbs modified by "EU" } & \multicolumn{3}{|c|}{$\begin{array}{r}\text { verbs with "EU" as object } \\
13.63\end{array}$} & \multicolumn{3}{|c|}{$\begin{aligned} & \text { verbs with "EU" as subject } \\
& 33.54\end{aligned}$} \\
\hline nl-exit & $\underline{15}$ & 10.70 & legislation + & $\underline{1}, \underline{346}$ & 10.77 & exit + & $\underline{210}$ & 9.41 & vote + & $1, \underline{322}$ & 10.28 \\
\hline ever-oppressive & $\underline{9}$ & 9.99 & funding + & $1, \underline{362}$ & 10.22 & reform & $\underline{98}$ & 8.88 & fulfill + & $\underline{489}$ & 9.71 \\
\hline pro & $\underline{8}$ & 9.48 & lie + & $\underline{489}$ & 9.87 & join + & $\underline{219}$ & 8.47 & like + & $\underline{489}$ & 9.66 \\
\hline uk-deprived & $\underline{6}$ & 9.39 & state + & $1, \underline{645}$ & 9.25 & leave + & $1, \underline{928}$ & 8.21 & encourage + & $\underline{490}$ & 9.59 \\
\hline quitting & $\underline{6}$ & 9.38 & project + & $\underline{523}$ & 8.78 & say + & $1, \underline{377}$ & 7.94 & knock + & $\underline{312}$ & 9.20 \\
\hline lean & $\underline{6}$ & 9.35 & membership + & $\underline{283}$ & 8.71 & quit & $\underline{53}$ & 7.67 & provide + & $\underline{370}$ & 8.93 \\
\hline dreaded & $\underline{6}$ & 9.29 & shackle + & $\underline{112}$ & 8.43 & blame & $\underline{44}$ & 6.78 & become + & $\underline{325}$ & 8.11 \\
\hline damaged & $\underline{6}$ & 9.13 & exit + & $\underline{171}$ & 8.37 & thank & $\underline{16}$ & 6.31 & rise + & $\underline{154}$ & 7.54 \\
\hline anti & $\underline{9}$ & 8.83 & referendum + & $1, \underline{153}$ & 8.22 & compare & $\underline{17}$ & 6.16 & be + & $\underline{6}, \underline{692}$ & 7.03 \\
\hline undemocratic & $\underline{7}$ & 8.39 & matter + & $\underline{114}$ & 8.07 & define & $\underline{15}$ & 5.90 & need + & $\underline{121}$ & 6.99 \\
\hline brussels & $\underline{28}$ & 8.21 & metaphor & $\underline{68}$ & 7.70 & oblige & $\underline{10}$ & 5.76 & have + & $\underline{2}, \underline{893}$ & 6.91 \\
\hline the & $\underline{12}$ & 7.24 & citizen & $\underline{92}$ & 7.44 & divide & $\underline{16}$ & 5.76 & grab & $\underline{36}$ & 6.31 \\
\hline old & $\underline{16}$ & 5.88 & fee & $\underline{66}$ & 7.43 & be + & $1, \underline{498}$ & 5.41 & take & $\underline{66}$ & 5.38 \\
\hline \multirow[t]{12}{*}{ whole } & $\underline{6}$ & 1.83 & army & $\underline{71}$ & 7.19 & rejoin & $\underline{7}$ & 5.21 & fail & $\underline{51}$ & 5.31 \\
\hline & & & migrant + & $\underline{106}$ & 7.19 & reactivate & $\underline{6}$ & 5.04 & hold & $\underline{16}$ & 4.77 \\
\hline & & & re-tweet & $\underline{44}$ & 7.10 & inform & $\underline{6}$ & 4.95 & force & $\underline{12}$ & 4.70 \\
\hline & & & rule & $\underline{79}$ & 7.06 & affect & $\underline{10}$ & 4.91 & disempowered & $\underline{10}$ & 4.48 \\
\hline & & & budget & $\underline{51}$ & 6.97 & run & $\underline{20}$ & 4.76 & emasculate & $\underline{10}$ & 4.48 \\
\hline & & & increase & $\underline{45}$ & 6.80 & demand & $\underline{6}$ & 4.40 & damage & $\underline{10}$ & 4.47 \\
\hline & & & treaty & $\underline{45}$ & 6.50 & know & $\underline{15}$ & 4.36 & wish & $\underline{10}$ & 4.45 \\
\hline & & & commission & $\underline{34}$ & 6.38 & bind & $\underline{6}$ & 3.69 & benefit & $\underline{12}$ & 4.37 \\
\hline & & & application & $\underline{26}$ & 6.30 & need & $\underline{10}$ & 3.52 & choose & $\underline{10}$ & 4.34 \\
\hline & & & charter & $\underline{22}$ & 6.09 & do & $\underline{34}$ & 3.44 & ruin & $\underline{9}$ & 4.31 \\
\hline & & & partner & $\underline{29}$ & 6.05 & give & $\underline{10}$ & 3.12 & keep & $\underline{10}$ & 4.30 \\
\hline & & & risk & $\underline{29}$ & 5.96 & allow & $\underline{9}$ & 2.89 & mean & $\underline{14}$ & 4.26 \\
\hline
\end{tabular}


Table 1 illustrates that the modifiers 'exit', 'ever-oppressive', 'pro', 'UK-deprived', 'quitting', 'lean', 'dreaded' and 'damaged' collocate strongly with 'EU' in the Leave campaign. Except for the collocates 'pro', 'lean', 'whole', 'Brussels' and 'exit', all the modifiers convey a negative stance towards the EU.

TABLE 1. Top 14 collocate modifiers of 'EU' in the Leave and Leave against EU corpus

\begin{tabular}{clcccccc}
\hline Rank & Modifier & Freq. & logDice & Rank & Modifier & Freq. & logDice \\
\hline 1 & nl-exit & 15 & 10.70 & 13 & old & 16 & 5.88 \\
2 & ever-oppressive & 9 & 9.99 & 14 & whole & 6 & 1.83 \\
3 & pro & 8 & 9.48 & & & & \\
4 & UK-deprived & 6 & 9.39 & & & & \\
5 & quitting & 6 & 9.38 & & & & \\
6 & lean & 6 & 9.35 & & & \\
7 & dreaded & 6 & 9.29 & & & \\
8 & damaged & 6 & 9.13 & & & \\
9 & anti & 9 & 8.83 & & & \\
10 & undemocratic & 7 & 8.39 & & & \\
11 & Brussels & 28 & 7.24 & & & \\
12 & the & 12 & 5.88 & & & & \\
\hline
\end{tabular}

The noun and verb collocates in the Leave campaign in Table 2 may be categorised semantically into the following groups: collocates related to the policy of the EU and responsibilities to the EU such as ('legislation', 'funding', 'state', 'project', 'membership', 'fee', 'rule', 'budget', 'treaty', 'commission', 'application', 'charter', 'partner'), collocates related to the repercussions on the UK ('lie', 'shackle', 'migrant'), collocates that constructed the EU negatively ('dreaded', 'damaged', 'undemocratic', 'old') and collocates that refer to the Brexit referendum ('referendum', 'exit', 'matter').

TABLE 2. Top 24 collocated nouns and verbs modified by 'EU' in the Leave and Leave against EU corpus

\begin{tabular}{llcccccc}
\hline Rank & Modifier & Freq. & logDice & Rank & Modifier & Freq. & logDice \\
\hline 1 & legislation & 1346 & 10.77 & 13 & fee & 66 & 7.43 \\
2 & funding & 1362 & 10.22 & 14 & army & 71 & 7.19 \\
3 & lie & 489 & 9.87 & 15 & migrant & 106 & 7.19 \\
4 & state & 1654 & 9.25 & 16 & re-tweet & 44 & 7.10 \\
5 & project & 532 & 8.78 & 17 & rule & 79 & 7.06 \\
6 & membership & 283 & 8.71 & 18 & budget & 51 & 6.97 \\
7 & shackle & 112 & 8.43 & 19 & increase & 45 & 6.80 \\
8 & exit & 171 & 8.37 & 20 & treaty & 45 & 6.50 \\
9 & referendum & 1153 & 8.22 & 21 & commission & 34 & 6.38 \\
10 & matter & 114 & 8.07 & 22 & application & 26 & 6.30 \\
11 & metaphor & 68 & 7.70 & 23 & charter & 22 & 6.09 \\
12 & citizen & 92 & 7.44 & 24 & partner & 29 & 6.06 \\
\hline
\end{tabular}

Table 3 shows the verbs which collocate with 'EU' used as an object in the Leave campaign. Verbs are used to assert a strong stance on what needs to be done to the EU. These include: 'reform', 'rejoin', 'join', 'leave', 'thank', 'blame', 'oblige', 'inform', 'reactivate', 'demand', 'bind', 'need', 'do' and 'give'.

TABLE 3. Top 24 verbs collocated with 'EU' as an object in the Leave and Leave against EU corpus

\begin{tabular}{llcccccc}
\hline Rank & Modifier & Freq. & logDice & Rank & Modifier & Freq. & logDice \\
\hline 1 & exit & 210 & 9.41 & 13 & be & 1,498 & 5.41 \\
2 & reform & 98 & 8.88 & 14 & rejoin & 7 & 5.21 \\
3 & join & 219 & 8.47 & 15 & reactivate & 6 & 5.04 \\
4 & leave & 1,928 & 8.21 & 16 & inform & 6 & 4.95 \\
5 & say & 1,377 & 7.94 & 17 & affect & 10 & 4.91 \\
6 & quit & 53 & 7.67 & 18 & run & 20 & 4.76 \\
7 & blame & 44 & 6.78 & 19 & demand & 6 & 4.40
\end{tabular}




\begin{tabular}{lllllccl}
8 & thank & 16 & 6.31 & 20 & know & 15 & 4.36 \\
9 & compare & 17 & 6.16 & 21 & bind & 6 & 3.69 \\
10 & define & 15 & 5.90 & 22 & need & 10 & 3.52 \\
11 & oblige & 10 & 5.76 & 23 & do & 34 & 3.44 \\
12 & divide & 16 & 5.76 & 24 & give & 10 & 3.12 \\
\hline
\end{tabular}

Table 4 illustrates verbs which collocate with 'EU' used as a subject. When the EU is the agent, its actions are portrayed as harmful by disempowering, emasculating, damaging, ruining, failing or forcing the UK.

TABLE 4. Top 24 collocate verbs with 'EU' as a subject in the Leave and Leave against EU corpus

\begin{tabular}{llcccccc}
\hline Rank & Modifier & Freq. & logDice & Rank & \multicolumn{2}{c}{ Modifier } & \multicolumn{2}{c}{ Freq. } & logDice \\
\hline 1 & vote & 1,322 & 10.28 & 13 & take & 66 & 5.38 \\
2 & fulfil & 489 & 9.71 & 14 & fail & 51 & 5.31 \\
3 & like & 489 & 9.66 & 15 & hold & 16 & 4.77 \\
4 & encourage & 490 & 9.59 & 16 & force & 12 & 4.70 \\
5 & knock & 312 & 9.20 & 17 & disempowered & 10 & 4.48 \\
6 & provide & 370 & 8.93 & 18 & emasculate & 10 & 4.48 \\
7 & become & 325 & 8.11 & 19 & damage & 10 & 4.47 \\
8 & rise & 154 & 7.54 & 20 & wish & 10 & 4.45 \\
9 & be & 6,692 & 7.03 & 21 & benefit & 12 & 4.37 \\
10 & need & 121 & 6.99 & 22 & choose & 10 & 4.34 \\
11 & have & 2,893 & 6.91 & 23 & ruin & 9 & 4.31 \\
12 & grab & 36 & 6.31 & 24 & keep & 10 & 4.30 \\
\hline
\end{tabular}

\section{REPRESENTATION OF THE EU IN THE REMAIN CAMPAIGN}

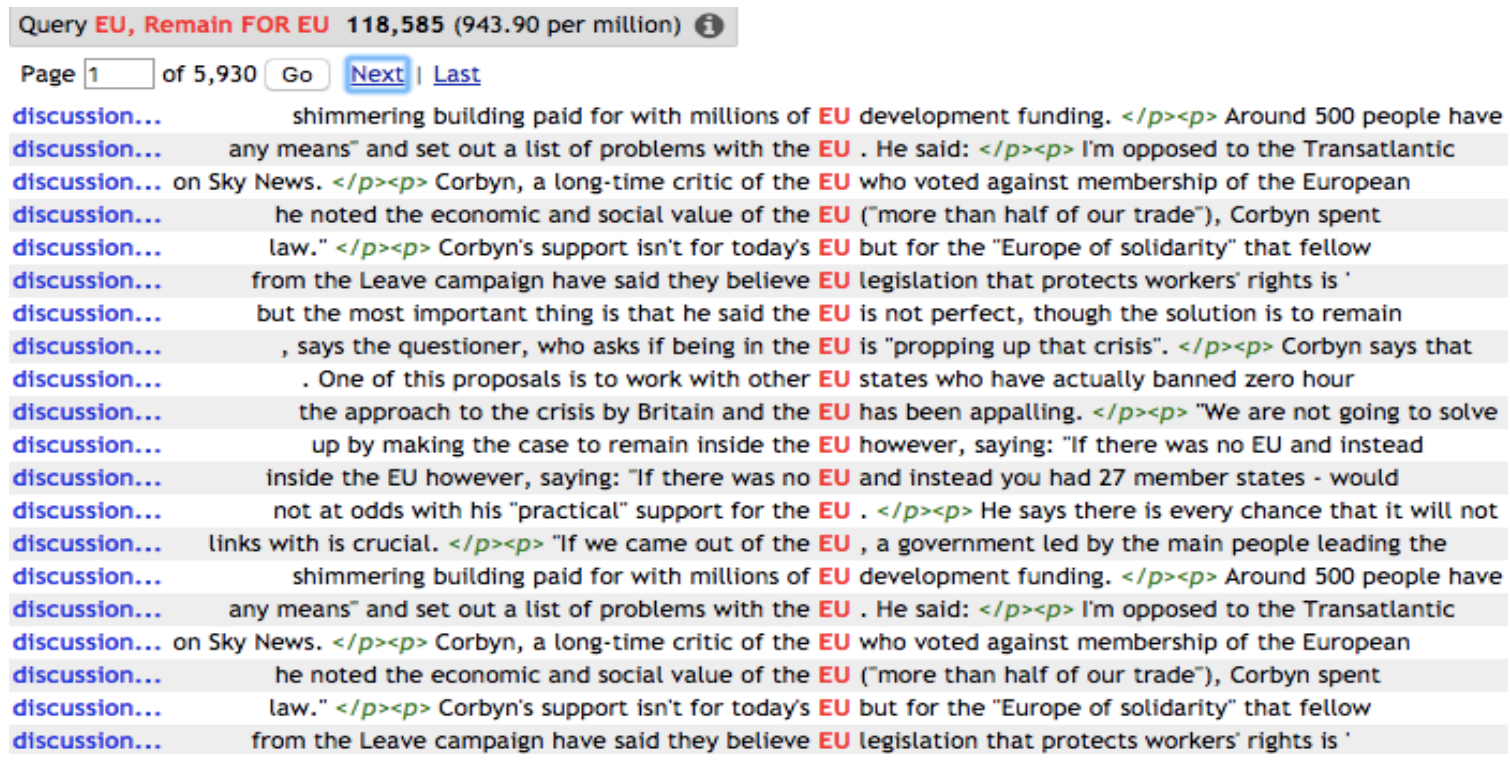

FIGURE 3. Concordance analysis of 'EU' in the Remain for EU corpus

Similar to the concordance analysis of 'EU' in the Leave campaign, 10 instances of 'EU' were selected randomly from the Remain campaign for close analysis. The numbers in the analysis below indicate the concordance lines of the 'EU' in Figure 3. The Remain campaign brings to light that famous author J.K. Rowling feels that leaving the EU is a form of a nationalism (line 1). The Remain campaign reminds the British public that Nigel Farage will be speaking against the EU at the Sage Gateshead, a music Centre built with EU funding (line 2). The stance of Jeremey Corbyn is not viewed as valid because of his early opposition to the UK joining the EU in its establishment, and his views are described as 'lukewarm' (line 3). Tim Roache, General Secretary of the General, Municipal, Boilermakers (GMB), a trade 
union, expresses his support for the best interests of the British workers by encouraging them to vote Remain in the EU referendum (line 4). The Guardian newspaper supports the Remain campaign and opposes the Leave campaign by promoting the liberal value of inclusion as the opposite of isolation, a motto of the Leave campaign according to the newspaper. According to the Guardian, the EU is about being united with countries which shares values with the UK (line 5).

The Remain campaign stresses the identity of the UK as unaffected by being in the EU; the UK is portrayed as having sovereignty, which sentiment is reinforced by the use of 'warts and all' (line 6). Accusing the Leave campaign of basing their plea to leave on emotion (namely, anger) and unsound judgment, the Remain campaign argues that it is for the best of British politics to negotiate for the UK's interests within the EU body rather than to do so outside of it, relying on the metaphors of 'inside the room' and 'knocking on the door' (line 7). Being in the Remain campaign is not equated to a full endorsement of EU politics; the EU is labelled 'undemocratic'. However, the Remain campaign has not given up on the EU and would like to reform it (line 8). Other topics associated with 'EU' include the benefits which being in the EU brings to professionals in the UK such as musicians; being part of the EU is portrayed as more beneficial to their interests and development (line 9). The Remain campaign calls for the nation to delve into the process of reforming the EU to fit the $21^{\text {st }}$ century as opposed to 'taking back control', a metaphor indicating regressive politics. The campaign instead stresses the agency of the UK (line 10).

Figure 3 shows the collocation analysis of the term 'EU', indicating frequencies of collocates, grammatical type, and $\log$ Dice results. The term 'EU' has the raw frequency of $148,686(5,454.78$ times per one million) in the Brexit corpus in the sub-corpus of Remain for EU.

\begin{tabular}{|c|c|c|c|c|c|c|c|c|c|c|c|}
\hline \multirow{2}{*}{\multicolumn{3}{|c|}{$\frac{\text { modifiers of "EU" }}{0.08}$}} & \multirow{2}{*}{\multicolumn{3}{|c|}{$\begin{array}{r}\text { nouns and verbs modified by "EU" } \\
22.24\end{array}$}} & \multirow{2}{*}{\multicolumn{3}{|c|}{$\begin{array}{r}\text { verbs with "EU" as object } \\
13.97\end{array}$}} & \multirow{2}{*}{\multicolumn{3}{|c|}{$\begin{array}{r}\text { verbs with "EU" as subject } \\
35.26\end{array}$}} \\
\hline & & & & & & & & & & & \\
\hline the & $\underline{10}$ & 7.07 & legislation + & $\underline{9}, \underline{312}$ & 12.64 & say + & $\underline{9}, \underline{330}$ & 10.59 & vote + & $\underline{9}, \underline{277}$ & 12.03 \\
\hline old & $\underline{18}$ & 6.08 & funding + & $\underline{9}, \underline{295}$ & 12.31 & be + & $\underline{9}, \underline{302}$ & 8.03 & be + & $\underline{30}, \underline{138}$ & 9.17 \\
\hline \multirow{23}{*}{ whole 1} & $\underline{14}$ & 3.06 & state + & $\underline{9}, \underline{395}$ & 11.44 & exit + & $\underline{194}$ & 7.99 & have + & $\underline{10}, \underline{508}$ & 8.70 \\
\hline & & & referendum + & $1, \underline{418}$ & 8.28 & leave + & 1,157 & 7.38 & knock + & $\underline{299}$ & 7.47 \\
\hline & & & lie + & $\underline{299}$ & 7.95 & join + & $\underline{116}$ & 6.76 & fulfill + & $\underline{299}$ & 7.43 \\
\hline & & & project + & $\underline{331}$ & 7.46 & endorse & $\underline{67}$ & 6.68 & like + & $\underline{299}$ & 7.41 \\
\hline & & & membership + & $\underline{240}$ & 7.45 & quit & $\underline{23}$ & 5.01 & encourage + & $\underline{304}$ & 7.41 \\
\hline & & & investment + & $\underline{169}$ & 7.21 & thank & $\underline{18}$ & 4.78 & become + & $\underline{332}$ & 7.16 \\
\hline & & & exit + & $\underline{146}$ & 6.92 & blame & $\underline{22}$ & 4.69 & rise + & $\underline{152}$ & 6.26 \\
\hline & & & citizen & $\underline{84}$ & 6.10 & do & $\underline{79}$ & 4.46 & make + & $\underline{115}$ & 5.16 \\
\hline & & & vote + & $\underline{264}$ & 5.96 & see & $\underline{52}$ & 4.40 & help & $\underline{43}$ & 4.02 \\
\hline & & & fee & $\underline{53}$ & 5.62 & compare & $\underline{14}$ & 4.34 & allow & $\underline{25}$ & 3.91 \\
\hline & & & integration & $\underline{63}$ & 5.49 & influence & $\underline{13}$ & 4.31 & create & $\underline{22}$ & 3.59 \\
\hline & & & remain & $\underline{50}$ & 5.47 & form & $\underline{13}$ & 4.06 & reach & $\underline{15}$ & 3.21 \\
\hline & & & migrant & $\underline{62}$ & 5.45 & brand & $\underline{10}$ & 3.96 & grab & $\underline{13}$ & 3.02 \\
\hline & & & official & $\underline{50}$ & 5.31 & claim & $\underline{9}$ & 3.67 & follow & $\underline{28}$ & 2.97 \\
\hline & & & debate + & $\underline{138}$ & 5.27 & reform & $\underline{8}$ & 3.60 & fail & $\underline{17}$ & 2.80 \\
\hline & & & law + & $\underline{120}$ & 5.13 & think & $\underline{10}$ & 3.51 & change & $\underline{12}$ & 2.78 \\
\hline & & & rule & $\underline{44}$ & 5.10 & hand & $\underline{8}$ & 3.44 & set & 11 & 2.70 \\
\hline & & & country + & 100 & 4.80 & feel & $\underline{8}$ & 3.40 & diminish & 10 & 2.64 \\
\hline & & & member & $\underline{60}$ & 4.74 & run & $\underline{12}$ & 3.33 & do & $\underline{34}$ & 2.63 \\
\hline & & & immigrant & $\underline{32}$ & 4.63 & call & $\underline{17}$ & 3.15 & recover & 10 & 2.63 \\
\hline & & & migration & $\underline{32}$ & 4.33 & give & $\underline{12}$ & 2.90 & go & $\underline{14}$ & 2.60 \\
\hline & & & regulation & $\underline{35}$ & 4.03 & have & $\underline{89}$ & 2.84 & provide & $\underline{11}$ & 2.52 \\
\hline & & & campaign + & $\underline{110}$ & 3.93 & need & $\underline{8}$ & 2.60 & need & $\underline{12}$ & 2.51 \\
\hline
\end{tabular}

FIGURE 4. Collocation analysis of 'EU' in the Remain for EU corpus 
Table 5 presents the collocate modifiers of 'EU' shared with the Remain campaign. These words carry a negative stance of the EU.

TABLE 5. Top 3 collocate modifiers of 'EU' shared by the Remain and the Remain for EU corpus

\begin{tabular}{lccc}
\hline Rank & Modifier & Freq. & logDice \\
\hline 1 & the & 10 & 7.07 \\
2 & old & 18 & 6.08 \\
3 & whole & 14 & 3.06 \\
\hline
\end{tabular}

Table 6, which presents the most common collocated nouns and verbs modified by 'EU' in the Remain campaign, shares some of the collocates with the Leave campaign regarding policy and responsibilities to the EU as well as the collocate 'lie'. However, the Remain campaign is distinct in its use of the collocates 'integration' and 'remain', which indicate positive attitudes towards the EU and migration to the UK.

TABLE 6. Top 24 collocated nouns and verbs modified by 'EU' in the Remain and the Remain for EU corpus

\begin{tabular}{llcccccc}
\hline Rank & Modifier & Freq. & logDice & Rank & Modifier & Freq. & logDice \\
\hline 1 & legislation & 9,312 & 12.64 & 13 & integration & 63 & 5.49 \\
2 & funding & 9,295 & 12.31 & 14 & remain & 50 & 5.47 \\
3 & state & 9,395 & 11.44 & 15 & migrant & 62 & 5.45 \\
4 & referendum & 1,418 & 8.28 & 16 & official & 50 & 5.31 \\
5 & lie & 299 & 7.95 & 17 & debate & 138 & 5.27 \\
6 & project & 331 & 7.46 & 18 & law & 120 & 5.13 \\
7 & membership & 240 & 7.45 & 19 & rule & 44 & 5.10 \\
8 & investment & 169 & 7.21 & 20 & country & 100 & 4.80 \\
9 & exit & 146 & 6.92 & 21 & member & 60 & 4.74 \\
10 & citizen & 84 & 6.10 & 22 & immigrant & 32 & 4.63 \\
11 & vote & 264 & 5.96 & 23 & migration & 32 & 4.33 \\
12 & fee & 53 & 5.62 & 24 & regulation & 35 & 4.03 \\
\hline
\end{tabular}

Table 7 presents the collocated verbs with 'EU' as an object in the Remain campaign. Some of the verb collocates are shared with the Leave campaign, including 'exit', 'leave', 'thank' and 'blame'. Of note is that, although the Remain campaign endorses the EU, the campaign expresses views of wishing to 'reform' the EU by verbs such as 'influence', 'form', 'brand' and 'call'.

TABLE 7. Top 24 collocated verbs with 'EU' as an object in the Remain and the Remain for EU corpus

\begin{tabular}{llllllll}
\hline Rank & Modifier & Freq. & logDice & Rank & Modifier & Freq. & logDice \\
\hline 1 & say & 9,330 & 10.59 & 13 & influence & 13 & 4.31 \\
2 & be & 9,302 & 8.03 & 14 & form & 13 & 4.06 \\
3 & exit & 194 & 7.99 & 15 & brand & 10 & 3.96 \\
4 & leave & 1,157 & 7.38 & 16 & claim & 9 & 3.67 \\
5 & join & 116 & 6.76 & 17 & reform & 8 & 3.60 \\
6 & endorse & 67 & 6.68 & 18 & think & 10 & 3.51 \\
7 & quit & 23 & 5.01 & 19 & hand & 8 & 3.44 \\
8 & thank & 18 & 4.78 & 20 & feel & 8 & 3.40 \\
9 & blame & 22 & 4.69 & 21 & run & 12 & 3.33 \\
10 & do & 79 & 4.46 & 22 & call & 17 & 3.15 \\
11 & see & 52 & 4.40 & 23 & give & 12 & 2.90 \\
12 & compare & 14 & 4.34 & 24 & have & 89 & 2.84 \\
\hline
\end{tabular}

Table 8 shows verbs which collocate with the term 'EU' as a subject in the Remain campaign. Some collocates are shared with the Leave campaign, such as 'fail', 'grab' and 'provide', yet the collocates are different in the sense that collectively these collocates fail to accumulate to form a consistent evidence that refer to the topic of investigation in the same way (Baker, McEnery \& Gabrielatos, 2007). Many verbs which collocate with 'EU' convey a 
positive, constructive image of the EU, including 'fulfil', 'encourage', 'allow', 'create', 'reach', 'change' and 'provide'.

TABLE 8. Top 24 collocate verbs with 'EU' as a subject in the Remain and the Remain for EU corpus

\begin{tabular}{llllllll}
\hline Rank & Modifier & Freq. & logDice & Rank & Modifier & Freq. & logDice \\
\hline 1 & vote & 9,277 & 12.03 & 13 & create & 22 & 3.59 \\
2 & be & 30,138 & 9.17 & 14 & reach & 15 & 3.21 \\
3 & have & 10,508 & 8.70 & 15 & grab & 13 & 3.02 \\
4 & knock & 299 & 7.47 & 16 & follow & 28 & 2.97 \\
5 & fulfil & 299 & 7.43 & 17 & fail & 17 & 2.80 \\
6 & like & 299 & 7.41 & 18 & change & 12 & 2.78 \\
7 & encourage & 304 & 7.41 & 19 & set & 11 & 2.70 \\
8 & become & 332 & 7.16 & 20 & diminish & 10 & 2.64 \\
9 & rise & 152 & 6.26 & 21 & do & 34 & 2.63 \\
10 & make & 115 & 5.16 & 22 & recover & 10 & 2.63 \\
11 & help & 43 & 4.02 & 23 & go & 14 & 2.60 \\
12 & allow & 25 & 3.91 & 24 & provide & 11 & 2.52 \\
\hline
\end{tabular}

\section{DISCUSSION}

\section{DISCOURSES OF BRITITSH SOVEREIGNITY}

The corpus-based discourse analysis of media representation of the EU referendum debates reveals discursive patterns and strategies associated with the EU in conflicting discourses over Brexit. The concordance analysis and the collocation analysis of 'EU' in Table 3 and 7 in the Leave and the Remain campaigns show that both campaigns recognise the very powerful role that the EU exercises in the UK and how that role affects the more individualised image of the UK in the eyes of the public. In the views held by the Leave campaign, the UK is not seen as a sovereign political entity protecting its own best interests evidenced by the verbs collocated with the EU in Table 4. On the contrary, the UK is seen as a follower of the EU agenda and policies in which the EU depicted negatively in the Leave campaign as seen in Table 1. Also, the Leave campaign delegitimises the EU by construing the EU as an undemocratic organisation in Table 1, a depiction also found by Weißbecker (2017). The Leave campaign further delegitimises the EU by describing it with very negative sentiments such as 'damaged', 'dreaded' and 'ever-oppressive'. The concordance analysis and the collocation analysis in Figure 1 also show that the effect of withdrawal from the EU is debated from common angles including the economy, the perspective of the British working class British workers and the stance of politicians and other famous figures in both the Leave and the Remain campaigns as seen in Figure 1 and 3.

\section{DISCOURSES OF EURO-SCEPTICISM}

Both the Leave and the Remain campaigns display some contempt towards the EU, yet they disagree on the proper course of action. In the Leave campaign, the concordance analysis in Figure 1 reveals a negative image of the EU in that relations with the EU are perceived as failing to benefit the UK and the EU's value systems are perceived as being different than the UK's. In the Remain campaign, a positive image is constructed about the values shared between the EU and the UK as seen in Figure 3. However, the Remain campaign expresses a desire to 'reform' the EU as a constituency, a point of view that is also held by the Leave campaigns as seen in Table 3, evidenced by the word 'reform' which is the second strongest collocate with the EU. Both of the campaigns are similar in sharing some populist rhetoric about the EU. Both express Euro-scepticism of the EU establishment in its current form; however, the views of the Leave campaign are more critical than the views of the Remain 
campaign. Although Euro-scepticism is also found in the Brexit discourse in social media by Ruzza \& Pejovic (2019), yet that scepticism had not only been substantiated by questioning the democratic credentials of the EU, it is however distinct in the findings of this study that Euro-scepticism has been shared between the two conflicting campaigns in the British media and the EU lacks support even to prospective Remain voters who expressed their views to 'reform' the EU.

\section{DISCOURSES OF RIGHT LEANING MEDIA VERSUS LEFT LEANING MEDIA}

The results of the analysis of the Guardian discourse in Figure 3 show that the Guardian leans towards views expressed in the Remain campaign and opposes the Leave campaign. This finding is in line with those of Thommessen's (2015) study, which highlights that the Guardian discourse focuses on othering as a discursive strategy. The Guardian newspaper paints the picture of two conflicting worldviews: the global and inclusive Remain campaign versus the nationalistic and misguided Leave campaign (Thommessen, 2015). Furthermore, an analysis of metaphors of agency such as 'taking back control' in Figure 3 reveals such metaphors to be associated with the Leave campaign and in the discourse of right-leaning broadsheets such as the Times (Thommessen, 2015). This particular metaphor was addressed in Zappettini's (2019) study, which found it used to legitimise a toxic argument that if the UK exits the EU, all policies beneficial to the EU will be deactivated, with the reasoning that the EU will be 'othered' and considered the outsider in this discourse.

\section{DISCOURSES OF THE UK AFTER BREXIT}

One of the notable findings in the Leave campaign is that its supporters believe in a version of the UK's future characterised by being better without the EU as seen in Figure 1. The Leave campaign uses a journey metaphor and collocates that express a wish for a UK that is free from the EU in Figure 1. The future of the UK with the EU is a future that is lacking conflicts and is going to be economically successful. A similar notion was addressed by Adler-Nissen, Galpin \& Rosamond's (2017) study, which also found that the Leave campaign legitimises their stance with the promise of a better future in the UK and the depiction of continued membership to the EU as a threat to that vision (Weißbecker, 2017).

\section{CONCLUSION}

The current study reveals that conflicting discourses of Brexit in media employ discursive patterns and strategies which express populist views about the membership of the UK in the EU. In conducting the comparative analysis of the Leave and Remain campaigns, this study explores similarities and differences in the discursive construction of the EU in the British media. Previous studies were found to be limited in scope, in particular lacking detailed accounts of how the EU is viewed in the two campaigns. Both the concordance analysis and the collocation analysis of 'EU' in the Leave and Remain campaigns have many analytical benefits. The corpus-based comparison of the Leave and the Remain campaigns serves to highlight dominant discursive patterns that pertain to discourses of British sovereignty, Euroscepticism, left and right media and the future of the UK after Brexit. In this study, collocation is found to be used for legitimisation purposes and the employment of collocations is a discursive strategy in commonly used in critical discourse studies (Wodak, 2015). In the four discourses pertaining to Brexit identified in this study, legitimisation is found to justify calls to exit the EU and to stay in the EU. This study notes that media discourses of Brexit might have been influenced by the populist rise in British media which it is found by many research to be indicative of increasing support of political parties adopting populist ideology which strives for 
division rather than unity (Bennett, 2019 and Tolson, 2019). Such views are alleged to stem from the financial instability of workers and from backlash to cultural change (Inglehart \& Norris, 2016). Even though the views of the two campaigns reflect two different ideological differences, yet it is distinct in this study that there seem to be some degree of similarities shared in both campaigns, in particular the way in which the EU is discursively constructed in a negative sense. In light of recent development, the UK has left the EU and the findings of this study provided insights for understanding the attitudes in the British media regarding the EU. The current study concludes that conflicting discourses of Brexit in media employ discursive patterns and strategies which might express populist views to legitimise their positions.

\section{REFERENCES}

Adler-Nissen, R., Galpin, C. \& Rosamond, B. (2017). Performing Brexit: How a Post-Brexit World is Imagined Outside the United Kingdom. The British Journal of Politics and International Relations. 19(3), 573-591.

Aluthman, E. S. (2018). A Corpus-assisted Critical Discourse Analysis of the Discursive Representation of Immigration in the EU Referendum Debate. Arab World English Journal. 9(4), 19-38.

Ballmann, K. (2017). Brexit in the News: Frames and Discourse in the Transnational Media Representation of Brexit (Unpublished MA dissertation). Stockholm University, Sweden, Stockholm.

Baker, P. (2006). Using Corpora in Discourse Analysis. A\&C Black.

Baker, P. (2010). Sociolinguistics and Corpus Linguistics. Edinburgh: Edinburgh University Press.

Baker, P., McEnery, T. \& Gabrielatos, C. (2007). Using Collocation Analysis to Reveal the Construction of Minority Groups: The Case of Refugees, Asylum Seekers and Immigrants in the UK Press. Corpus Linguistics 2007.

Baker, P., Gabrielatos, C. \& McEnery, T. (2012). Sketching Muslims: A Corpus Driven Analysis of Representations around the Word 'Muslim' in the British Press 1998-2009. Applied Linguistics. 34(3), 255-278.

Bennett, S. (2019). 'Crisis' as a Discursive Strategy in Brexit Referendum Campaigns. Critical Discourse Studies. 4(16), 1-16.

Clarke, J. \& Newman, J. (2017). 'People in this Country Have Had Enough of Experts': Brexit and the Paradoxes of Populism. Critical Policy Studies. 11(1), 101-116.

Firth, J. R. (1957). A Synopsis of Linguistics Theory. In Firth, J. R. (Ed), Studies in Linguistic Analysis. Oxford: Blackwell.

Gaston, S. \& Harrison-Evans, P. (2018). Mediating Populism, Demos, London. Retrieved from https://www.demos.co.uk/project/mediating-populism/

Hansson, S. (2018, July). Brexit and Blame Avoidance: Officeholders' Discursive Strategies of Self-preservation. Paper presented at Critical Approaches to Discourse Analysis Across Disciplines (CADAAD), University of Aalborg, Denmark.

Harris, J. (2018, Decemeber 10). Brexit? Britain's Divides Run far Deeper than that. The Guardian.

Retrieved from https://www.theguardian.com/commentisfree/2018/dec/10/brexit-divides-tensionspolitical-vote

Inglehart, R. F. \& Norris, P. (2016). Trump, Brexit, and the Rise of Populism: Economic Havenots and Cultural Backlash. HKS Working Paper No. RWP16-026. Available at: https://ssrn.com/abstract=2818659.

Koller, V., Kopf, S. \& Miglbauer, M. (2019). Discourses of Brexit. Milton: Routledge. 
Kilgarriff, A., Rychly, P., Smrz, P. \& Tugwell., D. (2004). The Sketch Engine. In Proceedings from EURALEX 2004, Lorient, France, 105-116.

Krzyżanowski, M. (2019). Brexit and the Imaginary of 'Crisis': A Discourse-conceptual Analysis of European News Media. Critical Discourse Studies, 1-26.

Leung, R. C. (2018). Analysis of The UK Prime Ministerial Discourse on Brexit: Thematic Choices and Their Implications. Discourse and Interaction. 11(2), 45-64.

Maccaferri, M. (2019). Splendid Isolation Again? Brexit and the Role of the Press and Online media in Re-narrating the European Discourse. Critical Discourse Studies, 4(16), 1-14.

Marchi, A. \& Taylor, C. (2009). If on a Winter's Night two Researchers: A Challenge to Assumptions of Soundness of Interpretation. Journal for Critical Approaches to Discourse Analysis across Disciplines. 3(1), 1-20.

O’Donnell, M. B. (2008) KWICgrouper: Designing a Tool for Corpus-driven Concordance Analysis. International Journal of English Studies. 8(1), 107-121.

Partington, A. (1998). Patterns and Meanings. Amsterdam, The Netherlands: John Benjamins.

Ruzza, C. \& Pejovic, M. (2019). Populism at work: the language of the Brexiteers and the European Union. Critical Discourse Studies. 4(16), 1-17.

Rychly, P. (2008). A lexicographer-friendly association score. In Proceedings of Recent Advances in Slavonic Natural Language Processing, RASLAN 2008, pages 6-9.

Sinclair, J. M. (1991). Corpus, Concordance, Collection. Oxford: Oxford University Press.

Sinclair, J. M. (1999). A Way with Common Words. In H. Hasselgard \& S. Oksefjell (Eds.), Out of corpora: A study in honour of Stig Johnsson (pp. 157-175). Amsterdam, The Netherlands: Rodopi.

Thommessen, L. (2015). 'Othering' the 'left-behind'? A Critical Discourse Analysis of the Representation of Leave Voters in British Broadsheets' Coverage of the EU Referendum. London, England: London School of Economics and Political Science (LSE).

Tolson, A. (2019). 'Out is Out and that's it the People have Spoken': Uses of Vox Pops in UK TV News Coverage of the Brexit Referendum. Critical Discourse Studies. 4(16), 1-12.

Weißbecker, E. (2017). A Discourse Analysis of the UK Referendum Campaign on EU Membership: The Case of Michael Gove's 'The Facts of Life say Leave' Speech. Berlin, Germany: The Institut für Europäische Politik (IEP).

Xiao, R. (2009). Theory-driven Corpus Research: Using Corpora to Inform Aspect Theory. In A. Lüdeling and M. Kytö (Eds.), Corpus Linguistics: An International Handbook (pp. 987-1007). Berlin, Germany: Walter de Gruyter.

Wenzl, N. (2018, July). 'This is about the Kind of Britain We Are': Discursive Constructions of National Identities in Parliamentary Debates about the UK's European Union Membership Referendum. Paper presented at CADAAD. University of Aalborg, Denmark.

Wodak, R. (2015). Critical Discourse Analysis, Discourse-historical Approach. In K. Tracy, C. Illie \& T. Sandel (Eds.), The International Encyclopedia of Language and Social Interaction. West Sussex: John Wiley \& Sons.

Zappettini, F. (2019). The Brexit Referendum: How Trade and Immigration in the Discourses of the Official Campaigns have Legitimised a toxic (Inter-) national Logic. Critical Discourse Studies. 4(16), 1-17.

Zappettini, F. \& Krzyżanowski, M. (2019). The Critical Juncture of Brexit in Media \& Political Discourses: From National-populist Imaginary to Cross-national Social and Political Crisis. Critical Discourse Studies. 4(16), 1-8. 


\section{ABOUT THE AUTHOR}

Reem Alkhammash (Ph.D.) is an Assistant Professor of Linguistics at Taif University. She obtained her PhD from Queen Mary University of London in Linguistics and an MA in Applied Linguistics from Essex University. She has achieved the status of Fellow (FHEA) from Advance HE. Her interests in scholarship include discourse analysis, medialinguistics, metaphor studies and gender and language. 